\title{
Moving Away from Coercion: Social Justice and Behavior Change in Disability Services
}

\author{
Bob Bowen 1 (), Elliot Bowen² \\ ${ }^{1}$ Prag Consulting, Melbourne, Australia \\ ${ }^{2}$ University of Maine, Orono, Maine, USA \\ Email: bob@matrixofneeds.com
}

How to cite this paper: Bowen, B. and Bowen, E. (2022) Moving Away from Coercion: Social Justice and Behavior Change in Disability Services. Health, 14, 194-203.

https://doi.org/10.4236/health.2022.142014

Received: January 10, 2022

Accepted: February 8, 2022

Published: February 11, 2022

Copyright (C) 2022 by author(s) and Scientific Research Publishing Inc. This work is licensed under the Creative Commons Attribution International License (CC BY 4.0).

http://creativecommons.org/licenses/by/4.0/

\begin{abstract}
The use of coercion to alter behavior in persons with intellectual and other developmental disabilities has a long history. Despite the work of leaders in the development of Positive Behaviour Support (PBS), the use of chemical, mechanical, physical or personal, and environmental restraints continues, resulting in traumatization, physical and emotional harm, and in some instances, death. When coercion is used, the trust between people breaks down, and the lack of trust is reinforced by the power differentials present when coercion occurs. Social justice provides an avenue for rebalancing power and regaining trust, but people affected by disabilities have historically been excluded from theories of social justice and, in some cases, do not fall within the definition of what it means to be a person in the paradigms put forth by a number of different authors. The term non-coercive has been used in an attempt to reframe behavior change theories and practices, but this term describes the absence of negative circumstances and interventions, rather than the presence of positive and affirming interactions which improve the quality of life of all stakeholders.
\end{abstract}

\section{Keywords}

Positive Behavior Support, Social Justice, Behavior Change, Coercion, Intervention, Interaction, Non-Coercive

\section{Introduction}

Nancy Ward is a woman living in the United States who self-identifies as a person with an intellectual disability, and also says that this disability is a part of who she is but it does not define her. Having known her for many years, to me she is Nancy. The descriptors I use about her are funny, reflective, creative, ana- 
lytical and colleague. We first met when I asked her to join an advisory committee on a project to eliminate the use of restrictive practices in support of individuals with a disability. She initially refused, as I was at the time working for an organization teaching the use of coercive and restrictive practices, and after several conversations, she agreed to participate on a provisional basis, eventually becoming a colleague in the process and added the role of a friend as our relationship continued over time.

Nancy and other colleagues have taught me the importance of contextualizing all abstract discussions such as this paper on coercion in the context of relationships with the end users of support systems for people affected by disabilities. Researchers, academics, clinicians, administrators and others can easily lose sight of the importance of this relational context and write about coercion without seeing and feeling the effects of coercive interventions on the day-to-day lives of real people.

Coercion is a pervasive element in almost all human societies. The laws that govern interactions between people rely on threats to maintain order, and anyone who goes against the desired order is punished in some way. This can be traced as far back as the philosophers of antiquity. The ideal society described by Plato in The Republic is one where "the proper officers will take the offspring of the good parents to the pen or fold, and there they will deposit them with certain nurses who dwell in a separate quarter; but the offspring of the inferior, or of the better when they chance to be deformed, will be put away in some mysterious, unknown place, as they should be ([1], p. 151)." What is troubling in the passage, as Ansorge ([2], p. 5) points out, is that "disability is present here only in the disappearance of the disabled."

History is filled with more examples of the exclusion of people affected by disabilities from theories of justice, even among prominent thinkers like Locke, Rawls, Pogge, and Singer, to name a few [2]. Rawls, for example, excludes from his theory of justice people with permanent physical disabilities or mental disabilities that he thinks prevent them from participating as full members of society. He states that in the idea of a society of fair cooperation "we assume that persons as citizens have all the capacities that enable them to be normal and fully cooperating members of society ([3], p. 234).”

The first article introducing the concept of Positive Behavior Support was entitled "Toward a Technology of 'Nonaversive' Behavioral Support" [4]. One of the important distinctions made in this article was the use of the term "behavior support" in place of the more commonly used phrases of "behavior management or behavior modification" which had been used to discuss addressing the maladaptive behavior of individuals with Autism Spectrum Disorders (ASD), Intellectual Disability (ID) and other diagnostic categories present in some people receiving specialized educational or residential services. Instead of modifying or managing behavior, the idea presented by Rob Horner and others [4] was that practitioners of positive behavior support would now seek to modify the envi- 
ronments in which behaviors occurred, focus on the quality of life experienced by the people being supported by this new behavioral approach, and understand that practitioners of Positive Behavior Support would do everything possible to move away from coercive interventions and embrace non-aversive behavior change methodologies [5].

The exclusion of people affected by disabilities from meaningful participation in the life of the larger community and their lack of value for the larger culture has been noted by people such as the eminent anthropologist Margaret Mead [6] and Wolf Wolfensberger, one of the most influential writers and researchers in the field of disability studies [7]. Because of the marginalization of people affected by disabilities, it is relatively easy to intentionally or inadvertently use coercion to change behavioral patterns when those behaviors have been identified as challenging or concerning [8]. The purpose of this article is to utilize social justice models to continue the shift from a service to a support model which uses interactions instead of interventions to support people who use behaviour to communicate the range of human emotions they are experiencing as a result of the use of coercive interventions to address their behavior [9].

\section{Methods}

This article was written by the authors using the experiences of the lead author as a behavioral consultant in North America, Europe and Australia and his knowledge of state, federal and national regulations. Literature searches were conducted using the search terms "disability, autism, coercive, coercion, behavior, intervention, interaction, justice, equity, and equality". Results which were included in the article were judged by the authors to be the clearest in presenting the differences between coercive and non-coercive interventions and the impact of social justice, or the lack thereof, on the quality of life of individuals affected by disabilities.

\section{Results}

\subsection{Disability and Theories of Justice}

Peer advocates and others have emphasized the importance of moving past the concept of non-aversive or non-coercive interventions through the use of social justice theory [10]. However, many theorists view people affected by disabilities are viewed as "postulated situations...having only the 'potential' to be human" ([11], p. 220). This is the result of the tendency to confine disability solely to the biomedical understanding, whereby all disabilities are of "natural origin," and therefore difficult or impossible to address the gross injustices across the globe. Failure to recognize the social dimensions of disability only exacerbates these injustices.

Interpersonal violence (IPV) of people affected by disabilities, including physical and sexual abuse, as well as "medication manipulation, refusal to provide assistance with essential activities of daily living, denial of access to telephones and 
other communication devices, and destruction of adaptive equipment" ([12], p. 302 ) is a significant issue. In 2013 alone, it is estimated that nearly $50 \%$ of people affected by disabilities experienced some form of IPV [13]. Restraint and seclusion are the most extreme examples of the use of coercion to change behavior, and are experienced by people affected by disabilities as IPV [14]. In a 26 year study of restraint associated deaths among people affected by disabilities the authors found that while the deaths were the result of individual interactions on a case by case basis, the deaths associated with the use of restraint were the result of a failure of organizational systems and processes [15]. These failures are part of organizational cultures which reflect the predominant ethos of the larger culture in which human services are provided and received [16]. Changes in policy and procedures, changes in training standards, changes in technique and technology will not be effective at reducing the use of coercion and IPV without first changing the culture of the organization. In order to achieve social justice for people affected by disabilities there must be a change in how people affected by disabilities are seen, or not seen, by the larger society.

Robert Murphy, who taught anthropology at Columbia University for over 30 years, retired in 1990. In his book The Body Silent [17], he chronicles the effect of his physical disability due to a spinal tumor on the ways people interacted with him, recognizing that at times he was invisible, and at times people treated him like a small child. He also recognized that his students were less fearful of him as his physical presentation as a man in a wheelchair was much different than as an able bodied man.

When Robert Edgerton received his Ph.D. in anthropology, he did so on the basis of his ethnographic study of 48 individuals affected by intellectual disabilities who had lived in a state institution, and now lived in community-based settings. While the paper and subsequent follow up are important, for purposes of this article it is the comments of a person writing a book review that most clearly sheds light on the lack of social justice afforded by people affected by disabilities. The reviewer states that "Because the subjects are so open and their lives so relatively simple, the basic components of a positive self-identify among these subjects appear more sharply than they do in normals [18]." This view of some individuals as "normal" and others as not fitting in the same category is echoed in the work of John Rawls, who restricts membership in an ideal society to people who can fully cooperate. It was Rawls' assumption that this would exclude some people affected by disabilities [19], though he never defended this assumption and he never sought to include people affected by disabilities in the processes of outlining the structure of society [20].

The predominant ethos of the culture, relative to people affected by disabilities, is reflected in the organizational cultures in which human services are provided and received. Because people affected by disabilities are seen as being lessless able, less visible, less intellectual, less competent, they are prone to being used, abused and coerced when their behavior is considered to be challenging, 
maladaptive, or concerning for their own health and safety and/or the health and safety of others especially during the Covid-19 pandemic [21].

\subsection{Moving Away from Coercion in Behavior Change Methodologies}

Self-injurious actions and aggressive behaviors are the two most often cited reasons for the use of coercive behavior change methodologies, and in order to stop these behaviours interventions are utilized which use the public health model of primary, secondary, and tertiary interventions, which translate in behavioral approaches to prevention, de-escalation, and intervention [22]. Despite decades of research, hundreds of articles and conference presentations on the subject of reductions in the use of coercive, restrictive practices, the data indicates that the use of such practices has not significantly decreased and in some cases has actually increased.

> In Australia, the National Disability Insurance Scheme (NDIS) supports approximately 484,000 people with disabilities. In a 12 month period from July 2020 through June 2021, the use of restraints increased by $240 \%$ over the previous year [23].

> In England, the use of restraint increased from 22,000 reports in 2017 to 38,000 reports in 2019 [24].

$>$ The United States does not have a centralized system for monitoring the use of restraint, seclusion and other coercive practices. Individual states such as Wisconsin, Texas, Illinois and Maryland have noted increases in the use of coercive practices similar to Australia and England.

In the Six Core Strategies for Reducing Seclusion and Restraint Use [25], the first strategy is to empower leadership to change organizational cultures in order to achieve meaningful reductions in the use of seclusion and restraint. Follow up papers [16] [26] have attested to the effectiveness of this approach, and while changing the larger culture would be ideal, it is beyond the scope of this paper.

Moving away from coercion is insufficient in and of itself to sustain prolonged culture change. In order to sustain any change efforts, there must be a positive reason for change, a moving towards instead of a moving away. Coercion is used in human service settings in response to behaviors that have been identified by those in authority as being problematic [27]. In order to maintain safety for individuals who are being supported by the organization and the staff who provide the support, organizations must move towards methodologies that are at least as effective at maintaining the safety of all stakeholders in the human service system, and hopefully more effective.

The pedagogy known as Invitational Education [28] provides the framework for a behavior change model that invites rather than coerces behavior change. Known as Invitational Healing [29], the model recognizes the legitimate need for safety for all people and proposes a methodology specifically for use in mental health and general health hospitals, but which can be adapted to other human service settings as well. 
The premise of Invitational Education is that education is the result of the interaction between two processes: Learning and Teaching. Learning is what learners do, and teaching is what teachers do. Invitational Healing, then, is the result of the interaction between two processes: Recovery and Treatment. In addition, there are five concepts through which the interactions between those seeking to recover and those seeking to provide treatment are filtered. They are Respect, Trust, Optimism, Caring, and Intentionality. All these processes can be seen more clearly in Figure 1.

The process of Invitational Healing, and of all human service interventions or treatments, is either supported or hindered by the culture of the organization [30]. The power of the culture to support or hinder changes in the use of coercive interventions was recognized as an important factor in reducing and, where possible, eliminating the need for restraint and seclusion in human service settings [31]. The impact of individual experiences of trauma must be a part of the organizational culture in order to support the move away from coercive and towards invitational practices. Organizations must embrace the idea that everything we do in our organization is informed and guided by an understanding of the neurobiological impact of trauma and the healing work of recovery and resilience [32].

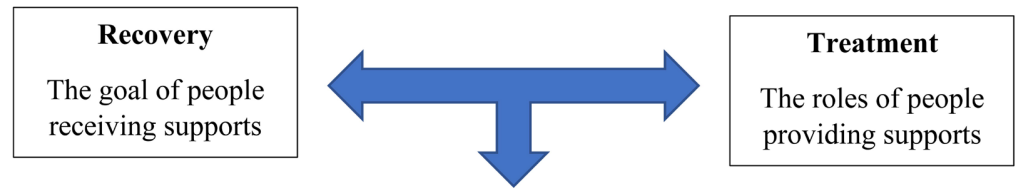

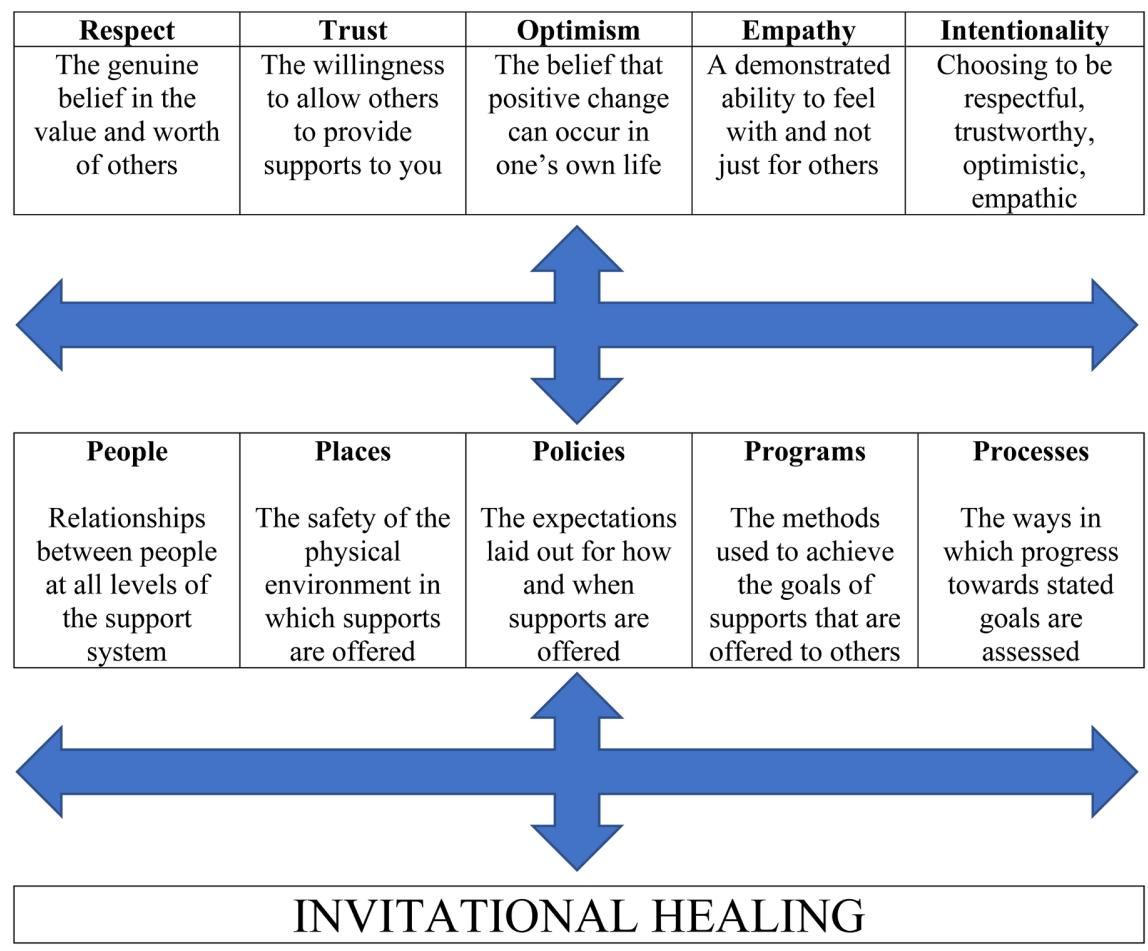

Figure 1. Visual model of the process of invitational healing. 


\section{Discussion}

The use of language is an important element in understanding the ways in which coercion is entrenched within organizations and systems [33]. The use of the word "intervention" continues the coercive approach of using power to intervene when those in positions of authority and/or responsibililty determine it is necessary. Interactions are relational in nature and are less hierarchical than interventions, which by their very nature interrupt the flow of a behavior and are coercive rather than supportive [34]. By offering treatments as part of a supportive and structured interaction with people rather than imposing treatments as an intervention, we can continue to move from a model of service delivery and towards a model of supportive interactions which support the people who use their behavior to achieve their own goals, using social justice models and values.

Coercive interventions undermine the work of recovery and resilience, as coercion is a retraumatizing event [35]. By moving towards the process of inviting behavior change, and away from coercion, we will continue the journey towards relationships that are truly equal and equitable. However, these relationships are often non-hierarchical in nature and contrary to the status quo of human services management. The human management model is, in fact, defined by a leading researcher in the field of developmental disability services as a way of structuring relationships in which the behavior of one group of persons is directed by another group of persons exercising authority over them [36].

The ancient Greek knew that there would always be opposition to upsetting the status quo of relational hierarchies, the ordered relationships in which people with power maintain their power through coercive interventions. The story of Prometheus exemplifies this, as Prometheus felt compassion for humans who were cold and stole fire from heaven to give it to people.

Many people are somewhat familiar with this story. What is less well known is that when Zeus had Prometheus chained to a rock as part of his punishment, Zeus selected two of his most trusted servants, Force and Violence, to restrain Prometheus. Every time we use coercion to threaten, punish, intimidate, warn or limit the behavior of others, we re-enact the story of Prometheus, holding on to our power at the expense of others.

This kind of shift will require a new paradigm best described as "allies in emancipation", which is the title of a book regrettably out of print but which nonetheless is deserving of our attention [37]. The human services system is one in which prepackaged services are offered to individuals receiving services, and inadvertently results in a supported employment program for staff. Transitioning to a model of support requires an individualized approach in which the focus is on what people need, not on what organizations can offer. It requires a continuation of the journey away from coercion and towards lives where people affected by disabilities have the same range of life choices as all other people in the society. 


\section{Conclusions}

In order for the work of organizational culture change to effectively support individual behavior change, the use of force and violence must be eliminated or at least highly restricted at all levels of the organization. A trauma informed organizational culture is one that is both hospitable and engaging at all levels of the organization [38], and one in which the values of respect, optimism, caring, trust and intentionality are not simply part of the training package, but everyday realities in the daily relationships between people, no matter their role, no matter their power, no matter their race or gender or sexual orientation or any of the other ways in which we differentiate human beings from each other.

Social justice for people with disabilities can exist anywhere, but it can only thrive in an environment in which the lived values of the organization are consistent with its written policies and procedures. It is the hope of the authors that this article will provide another opportunity to move away from coercion and towards an invitational approach to healing and behavior change and thus improve the quality of life of all people in the human service system and, hopefully, beyond.

\section{Human Subjects and Research}

No studies involving human beings or animals were conducted in the writing of this article. Nancy Ward gave permission for the use of her name in this article.

\section{Conflicts of Interest}

The authors declare no conflicts of interest regarding the publication of this paper.

\section{References}

[1] Plato (1973) The New Republic and Other Works by Plato. Anchor Books, New York.

[2] Ansorge, J.T. (2014) Global Disability: Reality, Theory, Practice. The Independent Living Institute, Stockholm.

[3] Rawls, J. (1991) Justice as Fairness: Political Not Metaphysical. Philosophy \& Public Affairs, 14, 223-251. https://doi.org/10.1007/978-1-349-21763-2_10

[4] Horner, R.H., et al. (1990) Toward a Technology of "Nonaversive" Behavioral Support. The Journal of the Association for Persons with Severe Handicaps, 15, 125-132. https://doi.org/10.1177/154079699001500301

[5] Vermont Division of Developmental Services (2004) Behavior Support Guidelines for Support Workers Paid with Developmental Services Funds.

https://ddsd.vermont.gov/sites/ddsd/files/documents/Behavior_Support_Guidelines 10\%272004.pdf

[6] Mead, M. (1953) National Character. In: Anthropology Today, University of Chicago Press, Chicago, 642-647.

[7] Wolfensberger, W. (2000) A Bried Overview of Social Role Valorization. Mental Retardation, 38, 105-123. https://doi.org/10.1352/0047-6765(2000)038<0105:ABOOSR $>2.0 . \mathrm{CO} ; 2$ 
[8] Sidman, M. (1993) Reflections on Behavior Analysis and Coercion. Behavior and Social Issues, 3, 75-85. https://doi.org/10.5210/bsi.v3i1.199

[9] Steinert, T., Noorthoorn, E.O. and Mulder, C.L. (2014) The Use of Coercive Interventions in Mental Health Care in Germany and the Netherlands. A Comparison of the Developments in Two Neighboring Countries. Frontiers in Public Health, 2, Article No. 141. https://doi.org/10.3389/fpubh.2014.00141

[10] Loewen, G. and Pollard, W. (2010) The Social Justice Perspective. Journal of Postsecondary Education and Disability, 23, 5-18.

[11] Arneil, B. (2009) Disability, Self Image, and Modern Political Theory. Political Theory, 37, 218-242. https://doi.org/10.1177/0090591708329650

[12] Hughes, R.B., Lund, E.M., Gabrielli, J., Powers, L.E. and Curry, M.A. (2011) Prevalence of Interpersonal Violence against Community-Living Adults with Disabilities: A Literature Review. Rehabilitation Psychology, 56, 302-319. https://doi.org/10.1037/a0025620

[13] World Health Organization (2007) Early Child Development: A Powerful Equalizer. World Health Organization, Malta.

https://www.who.int/publications/i/item/early-child-development-a-powerful-equal izer-final-report-for-the-world-health-organization-s-commission-on-the-social-de terminants-of-health

[14] Whittington, R. and Richter, D. (2006) From the Individual to the Interpersonal: Environment and Interaction in the Escalation of Violence in Mental Health Settings. In: Violence in Mental Health Settings, Springer, New York, 47-68. https://doi.org/10.1007/978-0-387-33965-8_3

[15] Nunno, M.A., McCabe, L.A., Izzo, C.V., Smith, E.G., Sellers, D.E. and Holden, M.J. (2021) A 26-Year Study of Restraint Fatalities among Children and Adolescents in the United States: A Failure of Organizational Structures and Processes. Child \& Youth Car Forum. https://doi.org/10.1007/s10566-021-09646-w

[16] Bowen, B. (2017) The Positive Practice of Safety: Reductions in Workplace Violence through Increases in Safety and Security at Organisational and Interpersonal Levels. In: The Routledge International Handbook of Forensic Psychology in Secure Settings, Routledge, London, 221-235. https://doi.org/10.4324/9781315673073-17

[17] Murphy, R.F. (2001) The Body Silent. WW Norton \& Company, New York.

[18] Gove, W.R. (1972) Reviewed Work: The Cloak of Competence: Stigma in the Lives of the Mentally Retarded. American Journal of Sociology, 78, 723-724. https://doi.org/10.1086/225382

[19] Stark, C.A. (2009) Contractarianism and Cooperation. Philosophy, Politics and Economics, 8, 73-99. https://doi.org/10.1177/1470594X08098872

[20] Richardson, H.S. (2006) Rawlsian Social-Contract Theory and the Severely Disabled. The Journal of Ethics, 10, 419-462.

https://doi.org/10.1007/s10892-006-9000-5

[21] Lund, E.M. (2020) Interpersonal Violence against People with Disabilities: Additional Concerns and Considerations in the COVID-19 Pandemic. Rehabilitation Psychology, 65, 199. https://doi.org/10.1037/rep0000347

[22] Bowen, B., Privitera, M.R. and Bowie, V. (2011) Reducing Workplace Violence by Creating Healthy Workplace Environments. Journal of Aggression, Conflict and Peace Research, 3, 185-198. https://doi.org/10.1108/17596591111187710

[23] Henrique-Gomes, L. (2021) NDIS Providers Used Unauthorized Restraints on Clients over a Million Times in 12 Months. The Guardian. https://www.theguardian.com/australia-news/2021/nov/10/ndis-providers-used-un 
$\underline{\text { authorised-restraints-on-clients-over-a-million-times-in-12-months }}$

[24] Abbot, M. and Clifton, H. (2020) "Inhuman" Use of Restraint on Disabled Patients. BBC News. https://www.bbc.com/news/uk-54848098

[25] Huckshorn, K.A. (2004) Reducing Seclusion \& Restraint Use in Mental Health Settings: Core Strategies for Prevention. Journal of Psychosocial Nursing and Mental Health Services, 42, 22-33. https://doi.org/10.3928/02793695-20040901-05

[26] LeBel, J.L., Duxbury, J.A., Putkonen, A., Sprague, T., Rae, C. and Sharpe, J. (2014) Multinational Experiences in Reducing and Preventing the Use of Restraint and Seclusion. Journal of Psychosocial Nursing and Mental Health Services, 52, 22-29. https://doi.org/10.3928/02793695-20140915-01

[27] Raveesh, B., Gowda, G. and Gowda, M. (2019) Alternatives to Use of Restraint: A Path toward Humanistic Care. Indian Journal of Psychiatry, 61, 693-697.

[28] Purkey, W. and Strahan, D. (1995) School Transformations through Invitational Education. Research in the School, 2, 1-6.

[29] Gooding, P., McSherry, B. and Roper, C. (2020) Preventing and Reducing "Coercion" in Mental Health Services: An international Scoping Review of English-Language Studies. Acta Psychiatrica Scandinavica, 142, 27-39. https://doi.org/10.1111/acps.13152

[30] Privitera, M.R., Bowie, V. and Bowen, B. (2015) Translational Models of Workplace Violence in Healthcare. Violence and Victims, 30, 293-307. https://doi.org/10.1891/0886-6708.VV-D-13-00119

[31] Anderson, E., et al. (2021) Influence of Organizational Climate and Clinician Morale on Seclusion and Physical Restraint Use in Inpatient Psychiatric Units. Journal of Patient Safety, 17, 316-322. https://doi.org/10.1097/PTS.0000000000000827

[32] American Psychological Association (2022) Organizational Challenges, Resilience, and Healing: 2016 Annual Report of the Policy and Planning Board. https://www.apa.org/about/governance/bdcmte/2016-policy-report.pdf

[33] Winn, B. (2014) Forcing Change: Should Leaders Use Coercive Strategies to Drive Cultural Change? Recent Academic Research on People and Strategy. People Strategy, 37, 9-18.

[34] Askeland, E., Forgatch, M.S., Apeland, A., Reer, M. and Grønlie, A.A. (2019) Scaling Up an Empirically Supported Intervention with Long-Term Outcomes: The Nationwide Implementation of Generation PMTO in Norway. Prevention Science, 20, 1189-1199. https://doi.org/10.1007/s11121-019-01047-9

[35] Bryson, S.A., et al. (2017) What Are Effective Strategies for Implementing Trauma-Informed Care in Youth Inpatient Psychiatric and Residential Treatment Settings? A Realist Systematic Review. International Journal of Mental Health Systems, 11, 36. https://doi.org/10.1186/s13033-017-0137-3

[36] Wolfensberger, W. (1975) The Origin and Nature of Our Institutional Models (Revised \& Illustrated Reprint of Chapter Entitled "The Origin and Nature of Our Institutional Models”. In: Changing Patterns in Residential Services for the Mentally Retarded, Human Policy Press, Syracuse, United States, 1-88.

[37] Sullivan, L. (2005) Building Alliances after Deleting Disabling Assumptions. In: Allies in Emancipation: Shifting from Providing Support to Being of Service, Thomas Dunmore Press, South Melbourne, 163-171.

[38] Harris, M.E. and Fallot, R.D. (2001) Using Trauma Theory to Design Service Systems. Jossey-Bass/Wiley, San Francisco. 